\title{
Social capital, civic engagement, and self-rated health in Ghana
}

\author{
Winfred A. Avogo 1 \\ Department of Sociology and Anthropology, Illinois State University, Campus Box 4660, \\ Normal Illinois, IL 61790, USA. \\ wavogo@ilstu.edu;
}

\begin{abstract}
This study uses data from southern Ghana to examine whether higher stocks of social capital through participation in civic groups matter for self-rated health. Drawing on social capital, the influence of social support, informal social control, direct participation in and reproductive health discussions within voluntary associations on self-rated health and reporting illnesses in the last six months prior to the survey are investigated. The findings show that social support and encouragement to use family planning significantly predict self-rated better health while informal social control and direct participation does not. Also, it is detected that while social control is associated with the likelihood of reporting illnesses within the last six months; direct participation in voluntary groups has the opposite effect. Lastly, women had lower predicted probabilities of self-rated better health and higher probabilities of reporting illnesses in the last six months than men. The findings are discussed in the context of the nuanced role of social capital on health and their implications for health promotion programs in resource constrained settings.
\end{abstract}

Keywords: Social capital, community organizations, voluntary associations, self-rated health, subSaharan Africa

\section{Résume}

Cette étude utilise des données du sud du Ghana à examiner si l'augumentation du capital social grâce à la participation de groupes importent pour l'état de santé autoévalué. Empruntant du capital social, l'influence de l'appui social, du contrôle social informel, de la participation directe à la reproduction et des discussions de la santé des associations bénévoles de l'état de santé autoévalué et les rapports des maladies au cours des six dernieres mois précédent le sondage, font l'objet d'une enquête. Les rêsultats montrent que le soutien social et l'encouragement à utiliser la planification familiale sensiblement prédire mieux l'autoévaluation de la santé, tandis que le contrôle social informel et la participation directe ne fonctionne pas. En outre, il est détecté alors que le contrôle social est associé à la probabilitéé de déclarer des maladies au cours des six derniers mois; la participation directe aux groupes bénévoles a l'effet inverse. Enfin, les femmes avaient prédit mieux les probabilités inférieures de l'autoévaluation de la santé et les probabilités plus élévées des rapports des maladies dans le dernier six mois que les hommes. Les conclusions sont examinées dans le contexte du rôle nuancé du capital social à la santé et leurs implications en matière de promotion de la santé dans un contexte des resources limitées.

Mots Cle: Capital Social, les organismes communautaires, les associations de bénévoles, l'autoévaluation de la santé, l'Afrique subsaharienne.

\section{Introduction}

This study investigates the association between social capital generated within voluntary community organizations and self-rated health in six communities in southern Ghana. It is located within the context of recent debates on community-level participation and health and the role of social capital in the maintenance of popu- lation health.

In recent decades, research that points to the limitations of individualistic approaches to population health (Friedman and Starfield 2003, Lomas 1998) and the failure of public health reforms to adequately tackle health behaviors (such as diet, exercise, smoking and depression), as well as widening income inequalities

I. Tel.: + I-309-438-5227; Fax: + I-309-438-5378. 
and their association with population health (Wilkinson 1996) in developed and developing countries has generated interest in the concept of social capital as a means of exploring the social determinants of health. Although fraught with conceptual ambiguities and dilemmas, much of the application of social capital to health is centered on the influential work of Robert Putnam, who defined the concept as features of a social organization such as social cohesion, social support, interpersonal trust, and norms of reciprocity that result from high levels of participation in civic groups. Such direct participation is known to improve efficiency by facilitating coordinated action for mutual benefit, especially in the consolidation of democracy (Putnam, Leonardi and Nanetti 1993).

In western settings, one of the major applications of social capital to health outcomes has been to explain the relationship between income inequality and health status. Kawachi and Kennedy (1997), for example, found that income inequality within a community was related to a reduction in voluntary group membership and social trust, which in turn was associated with increased rates of mortality. Other studies link higher levels of trust, reciprocity, and civic engagement with higher levels of selfrated health status (Kawachi, Kennedy and Glass 1999, Subramanian, Kim and Kawachi 2002), improvements in child health (Drukker et al. 2005), better mental health (Veenstra 2002), lower rates of smoking (Lundborg 2005) and lower crime rates (Kawachi, Kennedy and Wilkinson 1999).

In sub-Saharan Africa (as in most developing regions), although concepts such as "community participation", "civic engagement" and "community empowerment" are now well entrenched in mainstream health discourse (McKnight 1996, Flora and Gillespie 2009, Morgan 200I) and have captured the attention of international institutions (such as the World Bank and the World Health Organizations (WHO), empirical research on social capital generated through community-level participation and health is in its infancy and much remains to be learned about potential mechanisms that underlie this relationship. In Ghana, for example, the adoption of the Community-based and Health Planning Services (CHPS) system throughout the country attests to the importance of community participation in health (Nyonator et al. 2003). Yet, empirical research on social capital is mostly limited to sexual behavior and HIV risks. For example, one cross-sectional study on community-level influences on HIV infection in Southern Africa showed that different types of associational membership had an effect on HIV risks (Campbell, Williams and Gilgen 2002, Gregson et al. 2004), while a longitudinal study also suggests that different types of social capital (structural and cognitive) have potential benefits for HIV prevention through participation in formal and informal social institutions (Pronyk et al. 2008). Thus, beyond sexual behavior and HIV prevention little is known about how social capital generated within civic groups and individual socioeconomic characteristics and their interactions influence health outcomes, specifically self-rated health status and reporting health problems. Such work is essential in guiding and monitoring health promotion programs in the region.

Self-rated health status is an essential health outcome, even in developing countries, given evidence that simple subjective assessment of global health status adequately predicts disability and mortality in populations, in spite of known health risk factors (such as smoking) (Farmer and Ferraro 1997, Idler and Benyamini 1997). Although subjective, self-rated health holds psycho-social implications for overall health and well-being very similar to assessments of life satisfaction which is known to influence the prevalence of disease, disability, and cognitive and physical function (Kodzi et al. 20II). Moreover, objective or external assessments of health (by health practitioners) have been criticized from anthropological standpoints for being less sensitive to the meaning and interpretation of suffering and healing associated with illness (Sen 2002; Kleinman 1988; Kleinman 1995). Furthermore, due to previous research that indicates gender inequalities in social capital (Parks-Yancy, DiTomaso and Post 2006), interactions between social capital and gender may mediate differences in self-rated health and reporting illnesses but unfortunately, few (if any) studies have examined these interactions.

Using features of social capital as defined by Putnam (1993), such as direct participation in several types of voluntary associations, social support, informal social control, and reproductive health discussions within civic groups, this 
study investigates the health-enhancing (or lack thereof) benefits of associational membership in six communities in southern Ghana. Overall, the study probes how higher stocks of social capital, as conceptualized at the group-level, matter for individual self-rated health status and reporting illnesses in the six months prior to the survey after accounting for a range of individual and other community-level factors and their interactions.

\section{Conceptual framework}

Few concepts in social sciences evoke as much controversy as that of social capital. The controversies range from its imprecise conceptualization, appropriate means of measurement and level of analysis to its almost exclusive emphasis on the positive aspects of the concept (Portes 1998, Macinko and Starfield 2001). The conceptual framework of this study thus explores both the negative and positive consequences of social capital and is guided by the assumption that the unique contribution of social capital lies in its potential to use group-level associations to account for individual health outcomes (Kawachi et al. 2004). Thus, rather than conceived dichotomously as either an individual or community attribute, group-level mechanisms such as informal social control, social support (perceived and instrumental) from voluntary associations, intensity of associational links and social contagion are used to explore whether different dimensions of social capital may be associated with different aspects of health in different settings.

It is now widely accepted that two conceptual distinctions exist within social capital theory; 'bonding' and 'bridging' social capital. Bonding refers to social capital emanating from trusting and co-operative relations between members of a network who are similar in terms of their social identity (e.g. race, gender, and ethnicity), while bridging social capital refers to social ties between people who are unlike each other in social characteristics but nonetheless maintain relations of trust and mutuality. The former binds together homogeneous groups, while the latter interconnects heterogeneous groups (Putnam 2000). These two varieties of social capital parallel concepts such as "strong" and "weak" social ties as introduced by Granovetter (1973). Although difficult to meas- ure, distinguish or test empirically, the two varieties of social capital are consistent with grouplevel mechanisms utilized in this study and are helpful for outlining broad mechanisms linking social capital to self-rated health and reporting illnesses.

First, access to various forms of social support whether instrumental (providing access to cash loans or labor in kind) or cognitive (perceived social support and reciprocity) is more likely within smaller, tightly-knit community associations than in larger, more diverse and less cohesive groups that extend beyond the community. This aligns with the concept of bonding vs. bridging social capital. Much literature in social epidemiology attests to the health benefits of community participation through access to various kinds of social support (House, Landis and Umberson 1988). Applied to self-rated health status and reporting illnesses, it is expected that access to instrumental and cognitive social support provided by voluntary associations in deprived communities will enable individual and collective goods of associational members to be harnessed. These resources could be leveraged in the form of informal insurance that enables members to directly maintain their health and well-being. In rural areas of Ghana where most illnesses (such as malaria) are treated by self-medication, instrumental social support such as borrowing money for essential drugs or having access to means of transport to a health facility in emergency health situations might be more easily accessed in community associations characterized by high levels of social support. Furthermore, cognitive social support might indirectly strengthen group social identity, promote positive feelings towards others, improve perceptions of selfefficacy and engender self-esteem and empowerment (Campbell 200I). These psychological and social mechanisms have been found to mediate the relationship between perceived social support and individual physiological health (McEwen and Seeman 1999, Kawachi 2006).

The second focus of this framework is on informal social control as a form of social capital which is conceived to be more likely enhanced within tightly-knit voluntary associations. In previous literature, informal social control has been demonstrated to affect several non-health outcomes such as crime, juvenile delinquency and 
the risk of school dropout. Communities characterized by higher stocks of social capital also have lower crime rates due to the exertion of informal social control. Neighbors in such communities might be more eager to monitor and intervene in youth delinquent behaviors on street corners than in communities with lower stocks of social capital (Coleman 1988, Zhou and Bankson 1996). Applied to health outcomes, it is reasonable that neighbors in communities characterized by higher levels of social capital might intervene to report instances of drug use, alcohol abuse and underage drinking, thereby serving as a protective force against bad habits and reinforcing healthy behaviors (Kawachi 2006). However, consistent with the views of previous research, social control may likely exert a negative impact on self-rated health in resourced constrained settings due to excessive demands for conformity, and restriction of personal freedoms and autonomy (Portes 1998). For example, in tightly-knit religious groups, increasing levels of social control by enforcing strict compliance with religious behavioral norms (such as adherence to abstinence) might constrain individual autonomies and perhaps indirectly injure health.

The third primary feature of social capital in this study is not just membership in groups but the health benefits of frequent participation in activities of voluntary associations. Research has established that as citizens' political participation decreases so does their stock of civic skills required for the success of a democracy. Kawachi et al. (1997) found that as the levels of trust (whether most people can be trusted) within the U.S decreases, so does voter turnout in elections. Applied to health, voluntary participation in groups matters not just for political outcomes, but for policies geared towards alleviating poverty and improving opportunities for people to lead healthy lives (Kawachi 2006). Similarly, direct participation in closely-knit voluntary associations has been found to have psychological benefits independent of the presence of individual psychosocial resources, including self-esteem and efficacy and perceived social support (Rietschlin 1998). Consequently, it is expected that frequent participation in voluntary groups will improve self-rated health and be associated with respondents reporting fewer health problems.
The fourth focal point of the conceptual framework draws from previous research on the diffusion of innovations (Rogers 2003) and social networks, which has been usefully applied to contraceptive use, low fertility norms and HIV/AIDS related communication in developing countries. This research points to the spread of innovative behavior in communities and personal networks characterized by high levels of social capital (Agadjanian and Menjivar 2008, Kohler 200I). For example, Valente et al. (1997) concluded that women who were encouraged to use methods of family planning by their personal network members in voluntary associations were also more likely to use contraceptives themselves. Similarly, Clark (2010) concluded that men's extra-marital sexual behavior was associated with that of their best friends and friends with whom they talk about AIDS. Furthermore, social interaction within personal networks has been proved effective in providing information and exposure to the devastating consequences of HIV thereby stimulating behavior change to avoid infection (Avogo and Agadjanian 20 I3, Watkins 2004).

Thus, drawing from the literature on the potential effects of social interaction and personal networks on family planning behavior and health-related communication on AIDS, it is expected that encouragement within voluntary associations to use family planning and discussions on issues related to HIV/AIDS constitutes a direct source of social capital which could impact on self-rated health and reporting illnesses. Such encouragement and discussions provide social learning that enables women to take individual responsibility not only for their childbearing and sexual health but their overall health. This may yield additional benefits for building a sense of community, social empowerment, and self-efficacy.

Lastly, the expected associations as broadly outlined are likely to vary between women and men. Previous research has demonstrated that men have higher levels of social capital than women (Parks-Yancy, DiTomaso and Post 2006). Therefore, it is expected that the hypothesized health advantages of social capital as outlined in the framework will be amplified for men rather than for women.

Overall, the conceptual framework tests the following research hypotheses: 
HI: Respondents who receive social support from voluntary associations are less likely to report illnesses within the last six months and more likely to rate their health as better compared to those who did not receive social support, regardless of other factors and characteristics.

H2: Respondents who report social control from members of voluntary associations are more likely to report illnesses within the last six months and less likely to rate their health as better compared to those who report no social control, regardless of other factors and characteristics.

H3: Respondents who participate frequently in activities of voluntary associations are less likely than inactive participants to report illnesses within the last six months and more likely to rate their health as better, regardless of other factors and characteristics.

H4: Respondents who were encouraged to use modern family planning by members of voluntary associations are less likely than those who were not encouraged to report illnesses within the last six months and more likely to rate their health as better, regardless of other factors and characteristics.

H5: Respondents who report discussing issues of HIV/AIDS in their voluntary associations are less likely than those who did not to report illnesses within the last six months and more likely to rate their health as better, regardless of other factors and characteristics.

H6: Men with higher stocks of social capital are less likely than women to report illnesses within the last six months and more likely to rate their health as better, regardless of other factors and characteristics.

\section{Data and methods}

\section{Setting}

The study draws from the "Social Learning, Social Influence and Fertility Control" Household Surveys ("Cape Coast Diffusion Project") designed to study diffusion of fertility behavior in six communities located in the Central, Western, and Greater Accra regions of southern Ghana. The communities were purposively selected to represent diverse ecological, socioeconomic, ethnic, and kinship systems in southern Ghana. Four of the communities are inland with farming and trading as the predominant economic activities, while two are on the coast with fishing and trading as the economic activities of choice. Two of the communities located in the Greater Accra region close to the capital city Accra have a slightly higher socio-economic status (measured by the mean number of household possessions) than the rest. Educational attainment varies widely by community and gender. Male school attainment beyond the primary level ranges from $32 \%$ to $79 \%$, while that of females range from $27 \%$ to $58 \%$. Christianity is the dominant religion in all the communities except one, where $90 \%$ are Muslim (it is uncommon to find higher concentrations of Muslims along coastal areas in Ghana; Muslim communities are typically located in the interior of the country mostly to the north). Two broad ethno-linguistic groups can be identified; the Akan and $\mathrm{Ga}$-Adangbe with matrilineal and patrilineal systems of inheritance respectively. The majority of the respondents were married.

\section{Data}

The study draws from I,283 individual crosssectional cases collected in Round Six of data collection in $200 \mathrm{I}$ as part of a longitudinal study of the "Cape Coast Diffusion Project" that began in October 1998 and lasted until February 2003. Respondents in the six communities were selected using a variety of sampling techniques. In four of the relatively smaller communities, all households were enumerated in a household census and all women aged 18-50 and their coresident partners were selected for panel surveys. In the remaining two larger communities, simple random sampling was used to select households and all women aged 18-50 and their co-resident partners within those households were included in the panel surveys (Agyeman and Casterline 2003).

In addition to gathering information on respondents' background, childbearing and related reproductive health items such as contraceptive use, fertility preferences, social interaction and HIV/AIDS knowledge, attitudes and practices, detailed information was collected on respondents' self-rated health and reporting health problems since the last interview, among other health indicators. A separate module of the survey instrument was devoted to voluntary 
community based organizations and associations that exist within the six communities. The various associations could be classified as religious, social, cultural, economic or health associations. Each respondent was asked to identify seven potential community organizations or associations they have participated in in the recent past. Due to concerns of how long interviews could last without undue fatigue, further questions on their level of involvement, features and activities was limited to only four organizations. While a longitudinal investigation of the effects of social capital on health is preferred, at least to preserve the temporal order of the expected associations, this study is unable to do so effectively. Questions on the specific features of social capital examined here, although collected in round 6 and 8 of data collection, when included round 8 substantially reduced the sample size, thereby posing a threat to the valid estimation of coefficients.

\section{Measures}

Two dichotomous outcome measures of health are considered. The first outcome was coded from responses asking respondents "Since the last interview, have you had any health problems or illnesses?" A measure of whether or not respondents had had any health problems or illnesses since the previous interview (interviews were roughly six months apart) was thus created. The second outcome measured self-rated general health status. The survey instrument included the following question: "Overall, would you say that your health is better, about the same, or worse than at the time of the last interview?" Due to fewer cases that reported their health as worse (only 94 of 1284 cases reported that their health had worsened), a dichotomous outcome of whether or not the respondent was in better health vs. the same and worse health was created. In other words, this study modeled the probability of reporting better health vs. all else. Although doubts remain about the validity of using self-reports of health for assessing population health especially in poor settings due to the fact that disadvantaged populations might be less likely to report poor health compared to advantaged populations (Sen 2002), a recent study conducted in over 69 countries worldwide found evidence that self-reports of health may be useful for epidemiological investigations within countries, even in low income settings (Subramanian, Huijts and Avendano 2010). In addition, given previous evidence in developed settings that self-rated health adequately predicts subsequent mortality and disability (McGee, Liao, Cao and Cooper 1999) and has important psycho-social implications for health and well-being, the concept is worth exploring in resource constrained settings.

The main predictors of the study are five features of social capital as broadly laid out in the conceptual framework. First, respondents were asked "if the voluntary association(s) they belong to provide social support for its members such as monetary and instrumental assistance, offering advice, information and funeral support". Social support was thus measured as whether or not respondents received monetary or instrumental assistance, were offered advice, information, funeral support, etc. from any of the four associations vs. no support. Second, respondents were asked "Does [name of association] put pressure on its members in order to change or restrict members' attitudes to social issues?" Social control was constructed as a dichotomous measure of whether or not (any) association put pressure on its members in order to change or restrict members' attitudes to social issues. Third, respondents were asked "In the past year, how often have you attended meetings or participated in activities of [name of association]?" Frequency of participation in activities of voluntary associations was coded I if respondents participated in (any) associational activities once a month, several times a month, once a week and several times a week (active member or participant) and 0 if they did not participate at all, or participated once or on only a few occasions. Lastly, two questions were relied on to construct measures of social capital generated out of social interaction on family planning and HIV/AIDS within voluntary associations. Respondents were asked "Does [name of association] encourage use of modern contraception by its members?" A dichotomous measure was created of whether or not respondents were encouraged to use family planning. The survey also asked respondents "Does [name of association] discuss issues related to HIV/AIDS, such as how the disease is spread and how it can be prevented?" Thus a dichotomous measure 
was created with I representing whether respondents discussed issues related to HIV/ AIDS and 0 if they did not.

A set of individual- and household-level controls were included. These are: age and education coded in categories and employment (defined as any work outside the household for which they were paid in kind or cash), marital status and gender coded as dichotomies. Following previous studies that use household possessions as a proxy for household wealth in developing settings, we chose electricity supply to households (after testing other household items either separately or in combination) as an economic status indicator (Filmer and Pritchett 1999). Lastly, the community from which respondents were sampled was included as a control in itself and as a proxy, partly for ethnicity and lineage type.

\section{Statistical model}

Because all the outcome variables are dichotomies, binomial logit regression for multivariate modeling is used. It can be argued that due to the sampling design where individual respondents were selected from specific communities/ villages, respondents and their households may share with other respondents and households within the same communities some unobserved characteristics that may affect the associations of interest. As an alternative analytical strategy, rather than control for community (as a covariate), the intercept of each outcome variable was allowed to vary randomly by community and the models were fitted using the Glimmix procedure in SAS (9.3). However, the results obtained using both analytical strategies were identical. Thus for parsimony, the binomial logit models without the random intercept are reported.

In addition, relying on logistic regression to test hypotheses in this study poses an additional statistical challenge to interpreting the relationships observed since issues of endogeneity and multicollinearity are evident. This mainly arises from the fact that one has to be a member of a voluntary association to receive or partake in each of the five features of social capital. For example, only members can receive social support, be subject to social control, participate frequently in voluntary activities and engage in HIV/AIDS discussions. Thus the basic compari- sons are between members and non-members which do not have independent effects on the outcomes of the study. If, for example, a nonmember is excluded from one predictor, it automatically excludes that non-member from all other predictors in the model. This creates a problem of repeated discrete measurements that are correlated because they share a common category or characteristic (in this case being a member of a voluntary association). Failure to control for such biases may lead to improper inferences from regression parameters due to underestimated standard errors. Repeated Binary Logistic Regression (RBL) is therefore recommended in such situations and is implemented using the General Estimating Equations (GEEs) (Liang and Zeger 1986, Rungie and Laurent 2005) and fitted by the GENMOD procedure in SAS. For each outcome of the multivariate analysis, only a full model which includes all predictors and controls is presented.

Lastly, it must be noted that having undertaken these measures to minimize bias in the estimates, the cross-sectional nature of the data precludes causality and presents further challenges due to the temporal ordering of variables and the duration of exposure to measure the accumulation of social capital. Nonetheless, the results are illuminating.

\section{Results}

\section{Descriptive results}

In Table I, we first consider the frequency distribution and cross-tabulations of our predictors, controls, and outcomes variables. Overall, $48 \%$ of respondents reported illnesses in the last six months prior to the interview, compared to $62 \%$ who rated their health as better. On the distribution of features of social capital, the highest proportion was observed among respondents who reported receiving social support from voluntary associations (81\%). About $74 \%$ reported that they were active participants in their organizations, while $62 \%$ said they discussed HIV within their organizations. The lowest proportions were observed among respondents who reported social control within their associations (54\%) and those who were encouraged to adopt methods of modern family planning (42\%). On other sample characteristics, more than half the sample were aged 36 
years and above (54\%), 34\% had no schooling experience while $45 \%$ had secondary or more education. Thirty-four percent of the sample was male and the rest female (66\%). On measures of socio-economic status, the majority of the sample worked outside the household
(95\%) and had electricity supply to their households $(86 \%)$. Lastly, due to sampling variations, slight differences existed in the distribution of the sample by the six communities (range- I 1\%$22 \%)$.

Table I Percent distribution of features of social capital and individual characteristics by self-rated health and reporting health problems

\begin{tabular}{lll}
\hline & $\begin{array}{l}\text { Reported health } \\
\text { problems in last six } \\
\text { months }\end{array}$ & $\begin{array}{l}\text { Better self-rated } \\
\text { health }\end{array}$ \\
\end{tabular}

Features of social capital

$\begin{array}{llll}\text { Active membership } & 44.49 * * & 60.81 \dagger & 73.52 \\ \text { Social support } & 48.17 & 62.81 & 80.84 \\ \text { Social Control } & 48.78 & 60.00 \dagger & 54.13 \\ \text { Talked about HIV } & 47.99 & 61.4 & 62.15 \\ \text { Encourage family planning } & 46.88 & 68.2 * * & 42.37\end{array}$

Individual-level controls

Age

$\begin{array}{llll}16-25 & 49.44 & 57.22 & 14.02 \\ 26-35 & 45.57 & 61.82 & 31.62 \\ 36+ & 48.14 & 63.75 & 54.36\end{array}$

Education

No School

$52.56 * *$

60.23

33.49

I-6 years of school

49.64

63.41

21.50

7 or more years of school

43.37 **

62.72

43.46

Employed

47.55

61.99

95.48

Married

$46.31 *$

62.92

88.63

Male

$40.18 * *$

66.74*

33.72

Electricity supply to household

46.16*

63.05

86.28

Village-level controls

$\begin{array}{llll}\text { Community I } & 49.29 & 69.29 & 21.81 \\ \text { Community 2 } & 47.83^{*} & 71.01^{*} & 10.75 \\ \text { Community 3 } & 52.49 & 45.86^{* *} & 14.10 \\ \text { Community 4 } & 46 & 83^{* *} & 15.58 \\ \text { Community 5 } & 36.68^{* *} & 78.38^{* *} & 20.17 \\ \text { Community 6 } & 54.87^{*} & 24.34^{* *} & 17.60 \\ \text { tal (percent) } & 47.51 & 62.23 & \end{array}$

Chi-Square Significance: ** ${ }^{*} 0.01 ;$ *p0.05; † p I.0. N = I283

Column percentages does not add up to $100 \%$

Table I also displays cross-tabulations (column the independent variables and so does not add percentages are reported across categories of up to 100) of our predictors and outcomes of 
interests. As expected, a slightly smaller proportion of active members in voluntary organizations (45\%) reported health problems in the last six months prior to the interview compared to $55 \%$ of inactive members who reported health problems. This relationship was statistically significant by the chi-square statistic. Surprisingly, none of the other features of social capital were significantly associated with reporting health problems in the last six months. On self-rated health, individuals who were encouraged to use family planning within their voluntary associations were significantly associated with reporting a better health status (68\%). Active membership in and social control within voluntary associations were only marginally associated with better self-rated health $(61 \%$ and $60 \%$ respectively). Contrary to our conceptual model, receiving social support and discussions of HIV within associations while positively associated with better self-rated health were not found to be statistically significant by the chisquare statistic.

On the bivariate associations between our control and dependent variables, education, marital status and electricity supply to the household had a significant positive impact on self-reported health, while gender was significantly associated with both reporting health problems and self-rated health. For example, respondents with 7 or more years of school (43.4\%) were more likely to report health problems since the last interview compared to respondents who had no schooling (53\%). Married people $(46 \%)$ were less likely than nonmarried people to report illnesses. Respondents with electricity supply to their households (46\%) were less likely than those without electricity to report health problems. Lastly, males were less likely to report health problems than females and more likely to rate their health as better.

\section{Multivariate results}

Odds ratios from Repeated Binary Logistic Regression (RBL) are presented in Table 2. Each of the two models of the table corresponds to each outcome. In Model I, the likelihood of reporting a health problem or illness since the last interview is estimated. As observed from the table, the coefficient for social support received from voluntary associations although positive is not statistically significant. That of social control exerted on members for conformity is positive and only marginally significant $(p<0.10)$. The odds of reporting illnesses in the last six months among those who reported social control from associations is I.3 times that of those who did not. As observed in the bivariate relationships on Table I, active members of voluntary organizations are significantly less likely than inactive or occasional members to report health problems or illnesses, even after controlling for other characteristics. The odds of reporting health problems among active members of associations are $44 \%$ percent lower than those among inactive members of associations. Lastly, the coefficients for whether or not respondents were encouraged within their voluntary groups to use family planning methods and whether or not they discussed issues related to HIV/AIDS were not statistically significant. Thus Model I provides partial support for hypotheses two and three on the influence of social control and active participation on reporting illnesses but fails to support hypotheses one, four and five on social support, encouragement to use family planning and HIV discussions within voluntary associations respectively. On other effects, it is notable that respondents who received 7 or more years of schooling (secondary or higher education) as seen in the descriptive analysis had a marginally significant negative effect on reporting health problems as does having electricity supply to households. The effect of gender was negative and significant: men were $35 \%$ less likely to report a health problem or illness since the last interview compared to women. Lastly, respondents from community five, a farming community from the Fanti ethno-linguistic group in central region of Ghana were significantly less likely to report health problems since the last interview.

The odds ratios from the model predicting whether or not respondents reported being in better health from six months ago are presented in Model 2. Social support which was not significantly associated with reporting health problems in the previous model is now positive and significantly associated with a better health status: the odds of rating one's health as better among respondents who reported social support from voluntary associations are $43 \%$ higher 
than among those who reported no social sup-

port.

Table 2 Odds ratios of associations between features of social capital and selfrated health and reporting health problems

\begin{tabular}{|c|c|c|c|c|}
\hline & $\begin{array}{l}\text { I. Reported } \\
\text { health } \\
\text { problems in }\end{array}$ & & $\begin{array}{l}\text { 2. Better } \\
\text { self-rated } \\
\text { health }\end{array}$ & \\
\hline \multicolumn{5}{|l|}{ Features of associational social capital } \\
\hline Active membership & 0.56 & $* *$ & 0.70 & $*$ \\
\hline Social support & 1.14 & & 1.43 & $*$ \\
\hline Social control & 1.26 & $\dagger$ & 0.94 & \\
\hline Talked about HIV & 1.13 & & 0.81 & \\
\hline Encourage family planning & 0.92 & & 1.56 & **⿻丷木 \\
\hline \multicolumn{5}{|l|}{ Individual-level controls } \\
\hline \multicolumn{5}{|l|}{ Age } \\
\hline $16-25$ & 0.89 & & 1.00 & \\
\hline $26-35$ & 0.81 & & 1.03 & \\
\hline \multicolumn{5}{|l|}{ Education } \\
\hline I-6 years of school & 0.94 & & 1.04 & \\
\hline 7 or more years of school & 0.79 & $\dagger$ & 0.99 & \\
\hline Employed & 1.24 & & 0.54 & $\dagger$ \\
\hline Married & 0.84 & & 1.03 & \\
\hline Male & 0.65 & * & 1.31 & $\dagger$ \\
\hline Electricity supply to household & 0.73 & $\dagger$ & 1.00 & \\
\hline \multicolumn{5}{|l|}{ Village-level controls } \\
\hline Community 2 & 1.04 & & 1.16 & \\
\hline Community 3 & 1.07 & & 0.44 & ** \\
\hline Community 4 & 0.85 & & 2.33 & ** \\
\hline Community 5 & 0.52 & *** & 1.92 & ** \\
\hline Community 6 & 1.07 & & 0.16 & **⿻丷木 \\
\hline QIC* & |709.1I & & 1440.63 & \\
\hline
\end{tabular}

Notes: Reference categories: Inactive member, did not receive social support, did not discuss HIV, association does not encourage family planning, ages above 36, no education, not employed outside household, Female, No electricity, Community I, Significance Level: ** .01 ; *p.05; † p I.0. $\mathrm{N}=1283$

* Quasilikelihood under the Independence Model Criterion (QIC)

The coefficient for social control which was marginally associated with reporting health problems in the previous model is negative but not statistically significant in this model. Also, unlike the previous model, active participants in voluntary associations were surprisingly less likely to report that they were in better health than inactive members, even after controlling for other factors (this relationship was significantly significant): the odds of reporting better health status among active participants of voluntary associations are $30 \%$ lower than those among inactive members. Encouragement from voluntary associations to use family planning which was significant in the bivariate analysis is also highly significant in this model $(p<0.001)$ and positively associated with rating one's health as better: the odds of rating one's health as better among respondents who were encouraged within voluntary associations to use family plan- 
ning were $56 \%$ higher than among those who received no such encouragement. Lastly, the coefficient for whether or not issues of HIV/ AIDS were discussed within voluntary associations was not statistically significant. Thus in Model 2, partial support was found for hypotheses one and four which focused on the associations between social support and encouragement to use family planning from voluntary associations on self-rated health. Among other effects, employment outside the household was surprisingly negatively associated with rating one's health as better, whereas men were $31 \%$ more likely than women to report a better health status. Both effects were only marginally significant.

The goodness of fit statistics provided for comparing model fit in the General Estimating Equations (GEE) using the GENMOD proce- dure in SAS suggests that the models are correctly specified and provide an acceptable working correlation structure. For example, the QIC (Quasilikelihood under the Independence Model Criterion) for the full models showed lower values than the models with the intercept only (the model with the lower value is preferred).

To highlight and provide a visualization of gender differences in our dependent outcomes as observed in the multivariate analysis, Figure I plots predicted probabilities of reporting health problems and self-reported health. Overall, the figure reinforces female disadvantages in measurements of health: females have a lower predicted probability of self-rated health than males and a higher predicted probability of reporting health problems in the last six months.

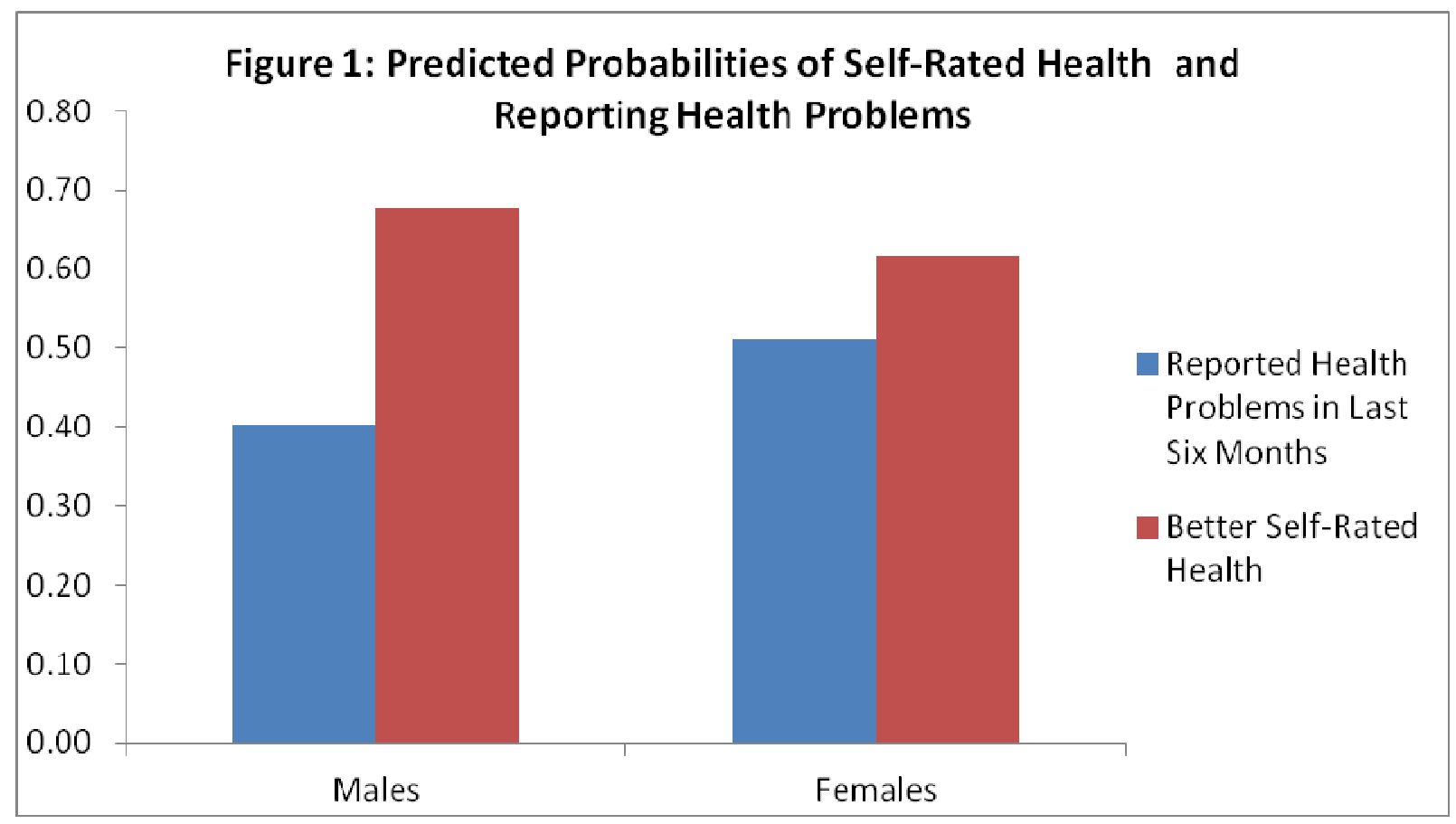

Lastly, as posited in hypothesis six, interaction effects between gender and measures of social capital on one hand and self-rated health and reporting health problems on the other were explored. Only one significant interaction effect of gender and social capital with self-reported health was found. Men who were encouraged to use family planning were $83 \%$ more likely to report that their health status is better compared to women who were encouraged to use family planning within their voluntary associa- tions $(p<0.10)$. (The results of these interactions are not shown but are available upon request.) This result provides some partial support for hypothesis six.

\section{Discussion and conclusion}

This study investigated the impact of higher stocks of social capital through participation in voluntary community organizations on self-rated health and reporting illnesses in six communities in southern Ghana. The limitations of rational 
choice theories of health promotion, especially in developing settings and the salience of the concepts of community participation and empowerment and its potential to influence health outcomes, provided the impetus to explore mechanisms through which social capital generated in voluntary groups may influence population health. The results indicate that a variety of broad measurements of social capital have a considerable effect on health but in different ways. Whereas social support and encouragement to use family planning significantly predicted self-rated better health, social control and direct participation did not. Also, it was detected that while social control was associated with the likelihood of reporting health problems within the last six months, direct participation in voluntary groups had the opposite effect. In addition to these effects, it was detected that gender had a direct impact on self-rated health and reporting illnesses and an interaction effect on social capital and health. Although these results must be interpreted with caution, due to the cross-sectional nature of the data and the existence of other unobserved factors that may influence self-rated health, the detected associations nonetheless point to the important and complex role features of social capital play in health outcomes.

First, the results highlight the complex and mixed consequences of social capital generated at the group-level and its influence on individual health outcomes. This is important given that previous research strongly emphasizes the positive consequences of social capital without a refinement to accommodate its less desirable effects. Yet some recent studies show that the same strong bonds that bind groups together for the collective good may also have negative implications for members (Portes 1998, Woolcock 1998). Thus, consistent with previous literature (Berkman and Glass 2000, Kawachi et al. 1997), social support, instrumental or cognitive, was found to be positively associated with selfrated health. The findings on social control however contradict some previous evidence that has shown some positive benefits of social control for mostly non-health outcomes (such as crime and juvenile delinquency) (e.g. Coleman 1998). Applied to health, social control did not have any impact on self-rated health and was marginally associated with respondents reporting ill- nesses in the previous six months. As asserted in the conceptual framework, access to social support afforded by membership in voluntary associations in developing settings may act as a form of social insurance that enables members to maintain their health. Similarly, at the psychosocial level, many voluntary associations work to empower members who are usually the most vulnerable to health risks to take initiatives and responsibility for their own health and wellbeing. These efforts, are likely to, over time, build general levels of perceived social identity, self-efficacy and self-esteem (Campbell 200I) which have been found to be associated with physical and psychological health. Support for these mechanisms seems to receive a boost by the finding in both the bivariate and multivariate analysis that encouragement from voluntary associations to use family planning is associated with rating one's health as better. This is consistent with research on the diffusion of innovations on family planning that finds that women who are encouraged to use modern family planning by their network members are also more likely to use contraceptives themselves (Valente et al. 1997).

Conversely, social control in bonded groups may entail excessive demands for conformity that may have negative implications for individual freedom and autonomy. Studies on social capital and sexual health in South Africa for example, find that while overall respondents who participate in local community organizations have a better chance of avoiding HIV, young men who belong to voluntary savings clubs were more likely to consume alcohol and be HIV-positive, and women of all ages who belonged to such clubs were more likely to have a casual partner and consume alcohol (Campbell, Williams and Gilpen 200I). Thus, this study not only contributes to emerging research that points to social capital as a mixed bag of risks and benefits, but it goes beyond investigating membership in different types of community organizations (as highlighted by Campbell, Williams and Gilpen 200I) to test several conceptualizations of social capital generated at the group level. Since measurements of social capital as conceptualized in the West remain unexplored in developing settings, this research offers valuable insights.

Second, consistent with the complex and 
mixed role of social capital in health, it is possible that different conceptualizations of social capital may have different effects on different health outcomes in different cultures and countries (Macinko and Starfield 200I). This assertion seems consistent with the findings of this study. For example, active membership in voluntary associations, which has consistently been associated with healthy social capital, has been found in this study to be negatively associated with reporting health problems and better selfrated health. Membership in voluntary associations, previous research has found, could reduce psychological stress beyond or similar to the effect of social support (Kawachi et al. 1999, Rietschlin 1998). However, this study finds that high levels of participation in voluntary groups may not, after all, yield positive effects on all health outcomes in all societies. Studies that test the relationship between several aspects of social capital and different health outcomes in varied population groups are needed if the concept of social capital must form part of the basis for crafting public health policy in developing settings.

Third, given that previous research has established gender differences in social capital resources for careers and employment (ParksYancy, DiTomasco, and Post 2006) and more recently, for sexual health behavior (Agadjanian and Menjivar 2008; Gregson et al. 2007), the finding that, overall, women have lower predicted probabilities of self-rated health and higher predicted probability of reporting health problems is not surprising. What might be illuminating, however, is the finding that men who were encouraged to use modern methods of family planning in voluntary groups were more likely to rate their health as better. This not only adds to the growing consensus that the concept of social capital is useful for exploring the broader and underlying social characteristics that determine health, but also has implications on how to foster health-enhancing social capital in poor settings.

In all, although, the value of self-rated health assessments for epidemiological investigations in developing settings may require further research to establish the social context within which such assessments occurs, the existing evidence in developed settings and the results obtained in this study gives reason to explore ways in which social capital may influence health policy. Combined with objective measurements of health, public health policy can adequately respond to and be more sensitive to the meaning and interpretation of suffering and healing associated with illness. First, although a complex resource, social capital can at the same time empower communities and impose obligations that may constrain health. Thus, health policy makers should not only heed the health enhancing qualities of social capital but should also focus health policy on its negative consequences. Frontline health workers should be trained on how to carefully build and foster healthy social relationships that reinforce not only instrumental but psycho-social elements of social capital while drawing attention to its possible constraints. Second, addressing deeply rooted cultural norms associated with gender and health within voluntary associations and identifying strategies that foster health-enhancing social capital for particularly women may help address gender inequalities in social capital and health.

Lastly, as cautioned, this study has limitations. The cross-sectional nature of the data and the lack of temporal ordering of variables not only prevent causal inferences but leave open alternative interpretations of our findings. Admittedly, the study leaves unsettled whether these communities were already characterized by higher stocks of social capital due to unobserved variables or social capital was fostered within these voluntary associations. Thus to ascertain the direction of causality, future studies must explore these relationships with longitudinal data. Second, the psycho-social mechanisms that the conceptual framework of this study hinges on may take a long time to manifest and require accounting for the duration of stay in voluntary groups in the statistical models. Lastly, the analysis may have omitted several other health related variables that maybe associated with self-rated health and reporting ill health. Nonetheless, the results are valuable as a first step to screening mechanisms that may be useful for follow up in longitudinal and in-depth studies.

\section{Acknowledgement}

Many thanks to John Casterline and the team of 
researchers from the University of Cape Coast in Ghana. Data collection for this research was supported by awards to the policy Research Division of the Population Council from the National Institute of Child Health and Human Development, the Andrew W. Mellon Foundation and the William and Flora Hewlett Foundation, and by an award to the University of Cape Coast from the Rockefeller Foundation.

\section{References}

Agadjanian, V. and Menjívar, C. (2008). "Talking about the epidemic of the millennium: religion, informal communication, and HIV/AIDS in SubSaharan Africa". Social Problems 55, (3): 30I-32I.

Agyeman, D., K. and Casterline, J., B. (2003). "Social organization and reproductive behavior in Southern Ghana". In Reproduction and Social Context in Sub-Saharan Africa:

A Collection of Micro-Demographic Studies. Ed. by Agyei-Mensah, S. and Casterline, J. B. Westport, CT: Praeger Publishers, 7-35.

Avogo, W. and Agadjanian, C. (2013) “Men's migration women's personal networks and responses to HIV/AIDS in Mozambique" International Journal of Environmental Research and Public Health. 10, (3):892-912.

Berkman, L., F. and Glass, T. (2000). "Social integration, social networks, social support, and health." in Social Epidemiology, ed by Berkman, L.F. and Kawachi, I. Oxford: Oxford University Press, 137-173.

Campbell, C., Williams, B. and Gilgen, D. (2002). "Is social capital a useful conceptual tool for exploring community level influences on HIV infection? An exploratory case study from South Africa". AIDS Care, I4, (I): 4I-54.

Campbell, C. (200I). "Social capital and health: contextualizing health promotion within local community networks". in Social Capital Critical Perspectives. Oxford University Press, I82-186.

Clark, S. (2010). "Extra-marital sexual partnerships and male friendships in Rural Malawi". Demographic Research, 22, I-28.

Coleman, J., S. (1988). "Social capital in the creation of human capital". American Journal of Sociology. 94, S95-121.

Drukker, M., Buka, S., Kaplan, M. and VanOS, J. (2005). 'Social capital and young adolescents' perceived health in different sociocultural settings". Social Science and Medicine 6I, ( I): 185198.

Farmer, M., M. and Ferraro, K., F. (1997). "Distress and perceived health: mechanisms of health decline”. Journal of Health and Social behavior, 39,
298-3II.

Filmer, D. and Pritchett, L. (1999). "The effect of household wealth on educational attainment: Evidence from 35 countries. Population and Development Review. 25, (I): 85-I 20.

Flora, C., B. and Gillespie, A., H. (2009). "Making health choices to reduce childhood obesity: community capitals and food fitness". Community Development, 40, II4-I 22.

Friedman, D., J and Starfield, B. (2003). "Models of population health: Their value for public health practice, policy and research". American Journal of Public Health, 93, 366-369.

Granovetter, M. (1973). "The strength of weak ties". American Journal of Sociology, 78, I 360- 1380.

Gregson, S., Terceira, N., Mushati, P., Nyamukapa, C. and Campbell, C. (2004). "Community group participation: can it help young women to avoid HIV? An exploratory study of social capital and school education rural Zimbabwe". Social and Medicine, 58, (I I):2119-2132.

House, J., S., Landis, K., R. and Umberson, D. (1988). "Social relationships and health". Science, 24I, 540-545.

Idler, L. and Benyamini, Y. (1997). "Self-rated health and mortality: a review of twenty-seven community studies". Journal of Health and Social Behavior, 38, (I): 21-37.

Kawachi, I (2006). "Social capital and community effects on population and individual health". Annals of the New York Academy of Sciences, 896,: 120-130.

Kawachi, I., Kennedy, B. P. and Glass, R. (1999). "Social capital and self-rated health: A contextual analysis". American Journal of Public Health, 89(8): II87-II93.

Kawachi, I., Kim, D., Coutts, A. and Subramanian, S., V. (2004). "Commentary: reconciling the three accounts of social capital". International Journal of Epidemiology, 33, 682-690.

Kawachi, I., Kennedy, B., P. and Wilkinson, R., G. (1999). Crime: Social disorganization and relative deprivation. Social Science and Medicine, 48, 719731.

Kawachi, I. and Kennedy, B., P. (1997). The relationship of income inequality to mortalitydoes the choice of indicator matter? Social Science and Medicine, 45, II 2 I- I I 27.

Kleinman A. (1988) The illness narrative: suffering, healing and the human condition. New York: Basic Books.

Kleinman A. (1995) Writing at the margin: discourse between anthropology and medicine. Berkeley: University of California Press.

Kodzi, I., A., Gyimah, S., O., Emina, J., B. and Ezeh, A., C. (20I I). "Understanding aging in sub- 
Saharan Africa: exploring the contributions of religious and secular social involvement to life satisfaction". Ageing and Society, 3I, 455-474.

Kohler, H-P. (200I). Fertility and social interactions: An economic perspective. Oxford University Press.

Liang, K., Y. and Zeger, S. L. (1986). "Longitudinal data analysis using generalized linear models". Biometrika, 73, 1322.

Lomas, J. (1998). "Social capital and health: implications for public health and epidemiology". Social Science and Medicine, 47, I I8I - I 88.

Lundborg, P. (2005). "Social capital and substance use among Swedish adolescents-an explorative study". Social Science and Medicine, 6I, (6): II5I1158.

Macinko, J. and Starfield, B. (200I). "The utility of social capital in research on health Determinants". The Milbank Quarterly, 79, 387427.

McEwen, B. and Seeman, T. (2006). "Protective and damaging effects of mediators of stress: elaborating and testing the concepts of allostasis and allostatic load". Annals of the New York Academy of Sciences, 896, 30-47.

McGee, D., L., Liao, Y. and Cooper, S., R. (1999). "Self-reported health status and mortality in a multiethnic US cohort. American Journal of Epidemiology, I49, 4I-46.

McKnight, J. (1996). The careless community: community and its counterfeits. Basic Books.

Morgan, L., M. (200I). "Community participation in health: perpetual allure, persistent Challenge". Health Policy and Planning, 16, 22I-230.

Nyonator, F., K., Williams, J., K., A., Phillips, J., F. and Jones, T., C. (2005). "The Ghana communitybased health planning and services initiative for scaling up service delivery innovation". Health Policy and Planning, 20, 25-34.

Parks-Yancy, R., DiTomaso, N. and Post, C. (2006). "The social capital resources of gender and class groups". Sociological Spectrum, 26, 85-II 3.

Portes, A. (1998). "Social Capital: Its origins and applications in modern sociology". Annual Review of Sociology 24, I-24.

Pronyk, P., M., Harpham, T., Busza, J., Phetla, G., Morison, L. A., Hargreaves, J. R., Kim, J. C., Watts, C. H. and Porter, J. D. (2008). "Can social capital be intentionally generated? A randomized trial from rural South Africa. Social Science and Medicine 67, (3), I559- 1570.

Putnam, R. D. (2000). Bowling alone: The collapse and revival of American community. New York: Simon

\section{\& Schuster.}

Putnam, R.D. (1993). "The prosperous community: social capital and public life". American Prospect, 24, 34-48.

Putnam, R., D., Leonardi, R. and Nanetti, R., Y. (1993). Making democracy work. New Jersey: Princeton University Press.

Rietschlin, J. (1998). "Voluntary association membership and psychological distress". Journal of Health and Social Behaviour, 39, 348-355.

Rogers, E., M. (2003). Diffusion of Innovations ( $5^{\text {th }}$ Edition). New York: Free Press.

Rungie, C., and Laurent, G. (2005). "Repeated binary logit: analyzing variation in behavioral Loyalty". Australasian marketing Journal, 13, 27-36.

Sen, A (2002). "Health: perception versus observation”. BMJ, 324, 860-86I.

Subramanian, S., Kim, D., Kawahci, I (2002). "Social trust and self-rated health in US communities: a multilevel analysis". Journal of Urban Health: Bulletin of the New York Academy of Medicine, 79(Suppl I), S2I-S34.

Subramanian, S., V., Huijts, T., and Avendano, M. (2010). "Self-reported health assessments in the 2002 World Health Survey: How do they correlate with education?" Bulletin of the World Health Organization, 88, I3I-I38.

Valente, T., W., Watkins, S.C., Jato, M.N., van Der Straten, A. and Tsitsol, P.M. (1997). "Social network associations with contraceptive use among Cameroonian women in voluntary associations". Social Science and Medicine, 45, 677-687.

Veenstra, G. (2002). Social capital and health (plus wealth, income inequality and regional health governance). Social Science and Medicine, 54, 849-858.

Watkins, S. C. (2004). "Navigating the AIDS epidemic in rural Malawi." Population and Development Review 30(4),:673-705.

Wilkinson, R, G. (1996). Unhealthy Societies: The Afflictions of Inequality. London, England: Routledge.

Woolcock M. (1998). "Social capital and economic development: toward a theoretical synthesis and policy framework. Theory and Society, 27:15I208.

Zhou, M. and Bankston, C., L (1996). "Social capital and the adaptation of the second generation: the case of Vietnamese youth in New Orleans". in The new second generation, ed. by A., Portes, New York: Russell Sage Foundation, 197-220. 